\title{
TRANSFER OF CELLULAR MATERIAL BETWEEN THE UTERINE EPITHELIUM AND TROPHOBLAST DURING THE EARLY STAGES OF IMPLANTATION
}

\author{
G. A. FINN AND A. M. LAWN \\ Physiology Department, Royal Veterinary College, University of London, and \\ Electron Microscope Department, Lister Institute of Preventative Medicine, \\ London
}

(Received 19th October 1967)

During the early attachment phase of implantation of the blastocyst, basically staining bodies are found in the uterine epithelium which have been described by Wilson (1963) as primary invasive cells. He postulates that they are cells passing from the embryonic trophoblast through the maternal epithelium into the uterine stroma. With the light microscope they appear as small, variably shaped, basically staining bodies in which no internal structure can be discerned. Finn \& McLaren (1967) have also reported the occurrence of these bodies during implantation but have suggested they be called W-bodies, a name which makes no assumptions about their structure or function.

The bodies are not common and do not appear in all sections through a blastocyst, or indeed in all blastocysts, at the appropriate stage of development. Wilson records a maximum of six bodies in one blastocyst. Their apparent scarcity may explain the absence of any record of such objects in recent papers on the ultrastructure of implantation in either the rat or mouse (Enders \& Schlafke, 1967; Reinius, 1967; Mayer, Nilsson \& Reinius, 1967).

Using the electron microscope we have made a thorough search for such bodies in sections through implantation sites taken from mice killed approximately $100 \mathrm{hr}$ after mating, and in this paper we describe structures in the maternal epithelium which show many features characteristic of $\mathrm{W}$-bodies. The structures were found in comparatively few sections and altogether only twelve have been observed. In the description that follows we shall for convenience refer to them as $\mathrm{W}$-bodies.

Plate 1 shows fairly low power micrographs of three of the structures. Typically they are considerably smaller and more electron dense than the surrounding epithelial cells and are not attached to the basement membrane. In some micrographs tongue-shaped processes of the trophoblast cells are seen extending from the blastocyst wall between the uterine epithelial cells and partially surrounding the bodies.

Even with the electron microscope the content of these bodies cannot always be clearly defined. Sometimes they contain a homogeneous darkly staining mass whilst at other times it is possible to recognize cell inclusions such as mitochondria and endoplasmic reticulum. A very common feature is the presence of large lipid droplets. Usually there is a characteristic re-arrangement of surrounding epithelial cells shown by an alteration in the pattern of the 
apical junctional complexes (Text-fig. 1). Junctional complexes (terminal bars) are always present immediately adjacent to the lumen between the lateral surfaces of contiguous endometrial epithelial cells. Where a W-body is found, junctional complexes radiate from it (Plates 1 and 2). The number of the complexes in any section indicates that the epithelial surface in the vicinity has been re-arranged for a considerable distance involving many cells.

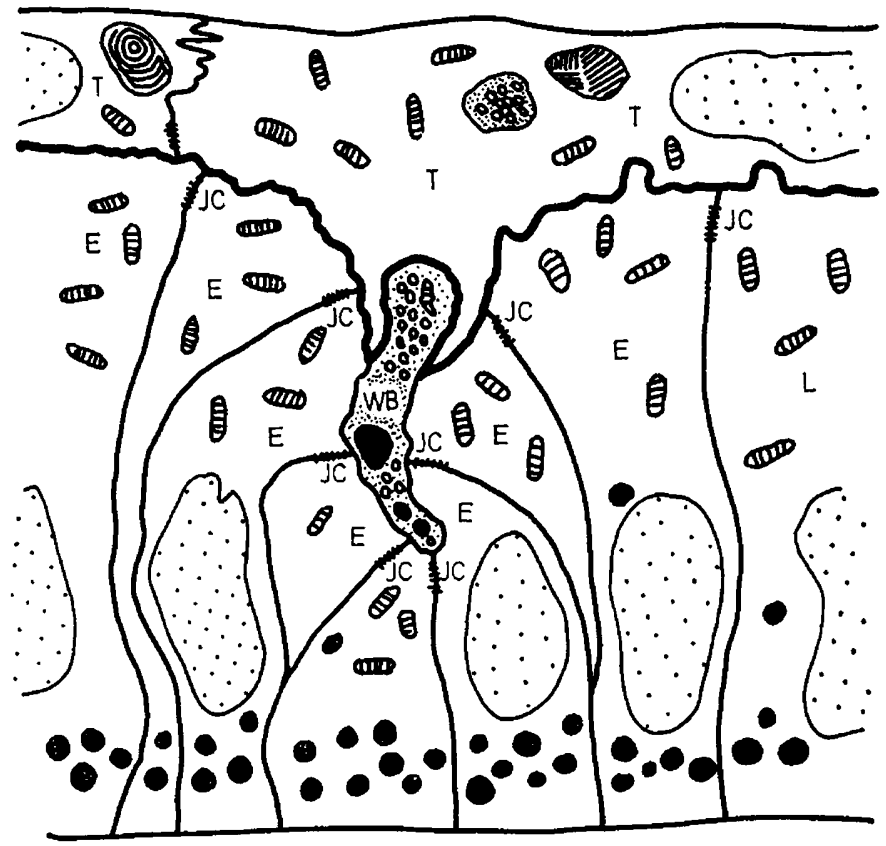

TEXT-FIG. 1. Diagram to show the relationship of the W-body to surrounding epithelial cells and to the trophoblast. T-trophoblast, $\mathrm{E}$-maternal epithelium, L-lipid, WB-W-body, JC- junctional complexes between the apices of uterine epithelial cells.

Similar, but much smaller, structures are also found within the trophoblast cells. In this situation they either appear homogeneous or have a membranous internal structure, often with myelin lamellae (Plate 2). They are surrounded by a distinct membrane.

It is not possible to state definitely whether the structures described in this paper are identical with the so-called primary invasive cells described by

\section{EXPLANATION OF PLATE 1}

T-trophoblast, E-maternal epithelium, L-lipid, WB-W-body, JC-junctional complexes between the apices of uterine epithelial cells. Arrows indicate the position of trophoblastic processes between uterine epithelial cells.

Fig. 1. Low power view of one W-body within the maternal epithelium and three in the trophoblast. $\times 5800$.

Frg. 2. A W-body deep within the maternal epithelium. A small trophoblastic process can be seen at the top of the picture. $\times 14,000$.

FIG. 3. A W-body within the maternal epithelium but half-surrounded by processes from the trophoblast at the end nearest to the maternal foetal junction. $\times 11,300$. 


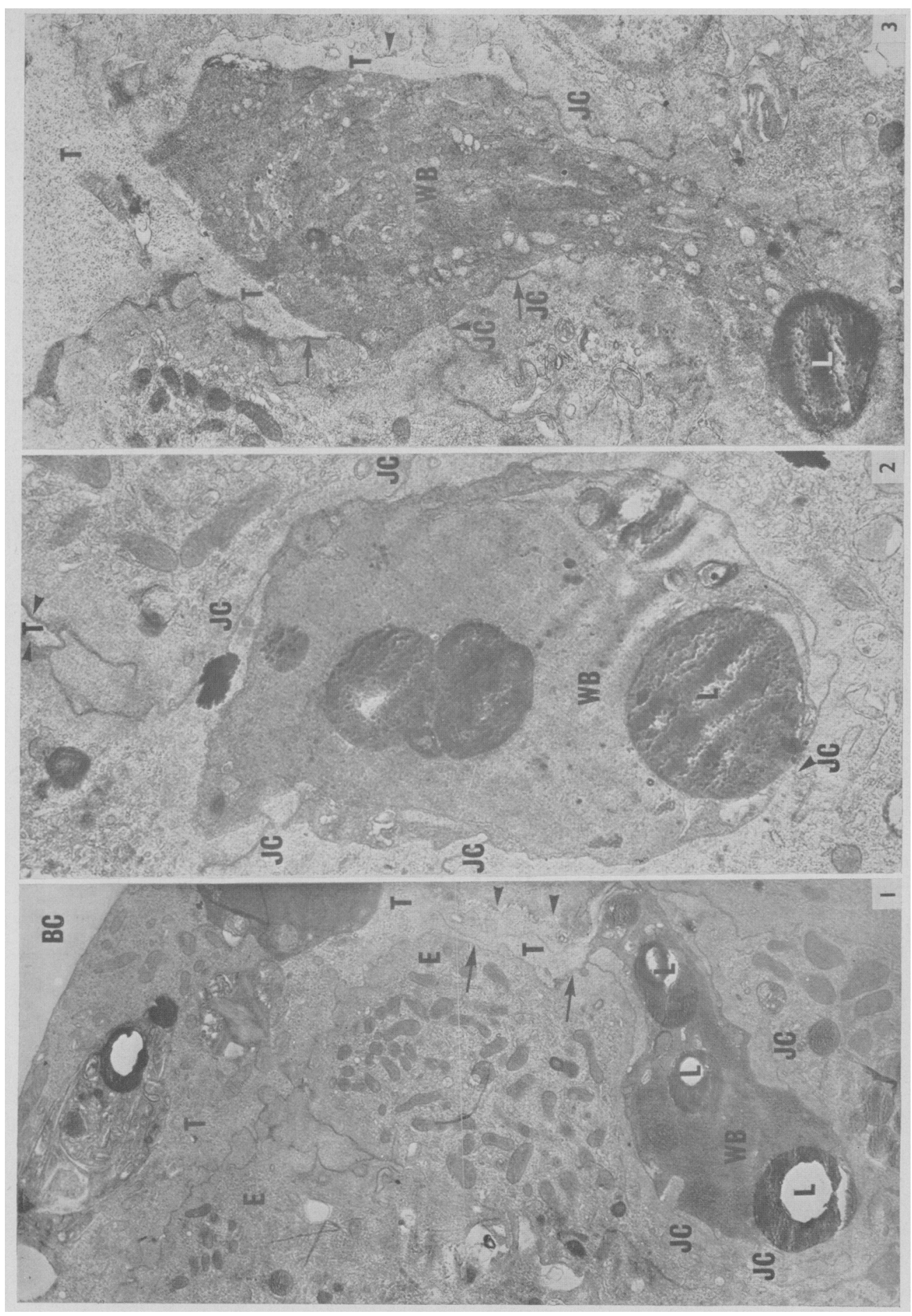

(Facing p. 334) 
PLATE 2

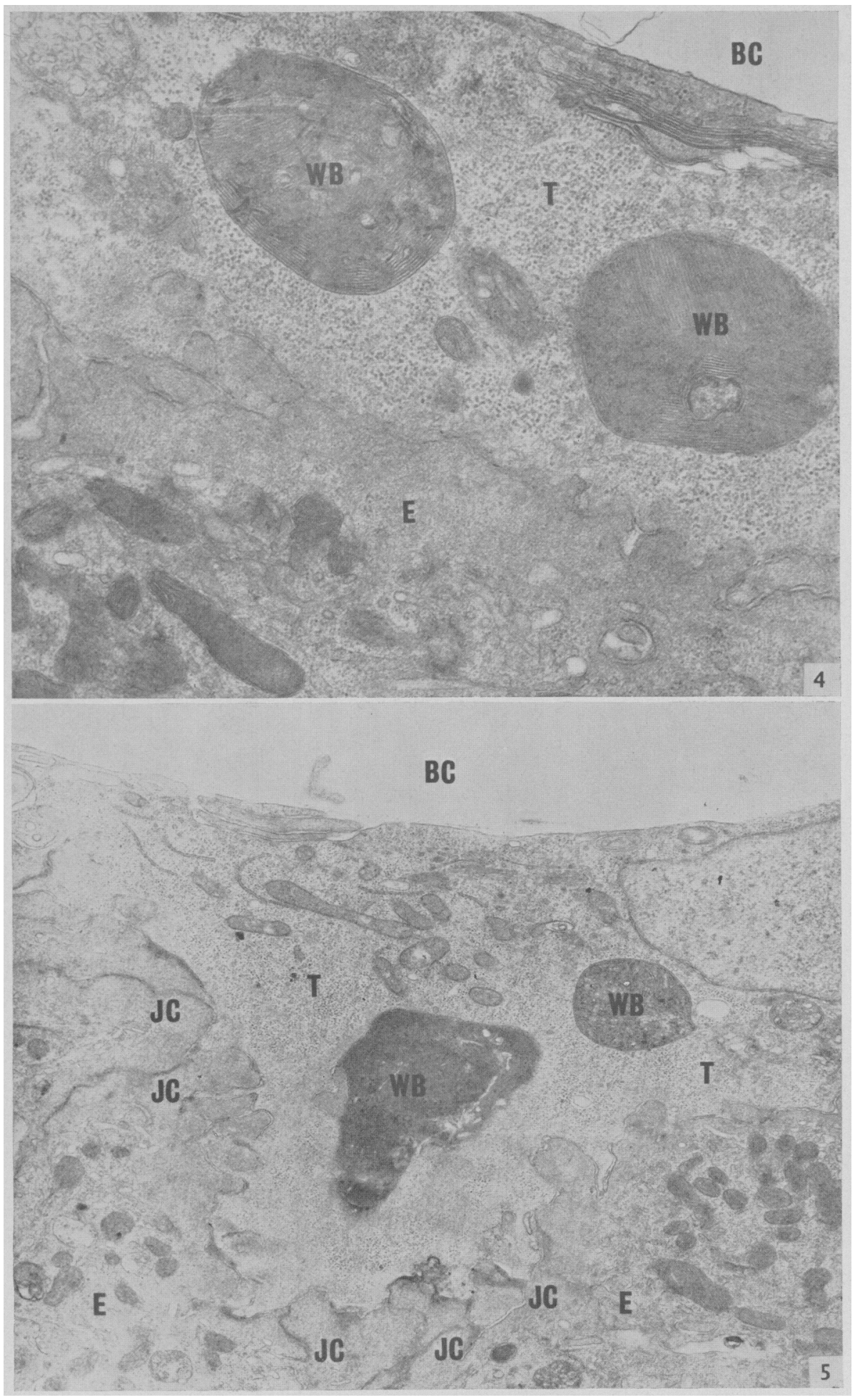

(Facing p. 335) 
Wilson (1963). However, since their position, shape and distribution are, in all essentials, similar this seems likely.

The evidence, from our electron micrographs, suggests that the bodies we describe are degenerating endometrial epithelial cells. Their varying contents can be explained as a series of stages in this degeneration, the final stage being unidentifiable membranous material embedded in a dense matrix. This process appears to involve dehydration: the resulting concentration of cell contents may account for the intense basophilia of these bodies. Their lipid granules closely resemble those of endometrial epithelial cells; granules with this appearance are not found within the trophoblast. Moreover, the changes in contiguous epithelial cells, as evidenced by alterations in the junctional complexes, seem to be more extensive than would be expected as the result of a passive response to a penetrating embryonic cell. For example, leucocytes can wander through an epithelium with little evidence of disorganization of its component cells. The changes seen near a W-body are suggestive of an attempt by the surrounding epithelial cells to re-establish a continuous epithelial barrier.

The presence of a process from the trophoblast surrounding the apex of some of these bodies (PI. 1, Figs. 1 and 3), and of inclusions (phagosomes) deeper within the trophoblast cells resembling those of the more degenerate bodies, indicates that they are phagocytosed and digested by the embryo. It is a matter for speculation whether the outgrowth of trophoblast is the result of a mechanical fault in the surrounding epithelium due to the presence of an effete cell, or whether it results from a chemotactic influence, but its presence might explain the observation that in paraffin-embedded material the embryo is frequently attached to the epithelium at the site of a body yet shrunken away elsewhere.

It is interesting that this type of degeneration, associated with dehydration and condensation of the degenerate cell, is found only if neighbouring cells are viable. When, later in implantation, the whole endometrial epithelium in the implantation chamber is sloughed and degenerates, the cells appear swollen and vacuolated before they are similarly engulfed by the embryo.

In summary, using the electron microscope, we have observed structures which we interpret as degenerate epithelial cells passing from the endometrium into the trophoblast, but we have not been able to find any evidence of cells passing in the reverse direction. We cannot, however, deny the possible existence of primary invasive cells as described by Wilson, especially as it is not feasible to examine a large quantity of material with the electron microscope. Further investigation of this problem is indicated in view of its considerable importance in understanding the mechanism of implantation.

\section{EXPLANATION OF PLATE 2}

T-trophoblast, E-maternal epithelium, BC-blastocyst cavity, WB-W-body, JCjunctional complexes between the apices of uterine epithelial cells.

Fig. 4. Two inclusions within the trophoblast, which probably represent the later stages of digestion of engulfed W-bodies. $\times 26,000$.

Fig. 5. Two inclusions within the trophoblast, the larger one probably represents an early stage following engulfment of a W-body. $\times 11,300$. 
This work was supported in part by United States Public Health Grants Nos. RG064889 and HD01476 from the National Institutes of Health, Bethesda, Maryland, U.S.A., a personal grant to one of the authors (GAF) from the Medical Research Council and a grant from the Fleming Fund for Medical Research.

\section{REFERENCES}

ENDERS, A. C. \& SChLAFKe, S. (1967) A morphological analysis of the early implantation stages in the rat. Am. F. Anat. 120, 185.

FinN, C. A. \& McLaren, A. (1967) A study of the early stages of implantation in mice. F. Reprod. Fert. 13, 259.

Mayer, G., Nrzsson, O. \& Reinius, S. (1967) Cell membrane changes of uterine epithelium and trophoblasts during blastocyst attachment in rat. Z. Anat. EntwGesch. 126, 43.

ReINIUs, S. (1967) Ultrastructure of blastocyst attachment in the mouse. Z. Zellforsch. mikrosk. Anat. 77, 257.

WiLson, I. B. (1963) A new factor associated with the implantation of the mouse egg. F. Reprod. Fert. $5,281$. 